\title{
Identification of Trichoderma spp. by DNA Barcode and Screening for Cellulolytic Activity
}

\author{
Abdelmegid I Fahmi ${ }^{1 *}$, Ragaa A Eissa ${ }^{1}$, Khalil A El-Halfawi ${ }^{2}$, Hanafy A Hamza ${ }^{2}$ and Mahmoud S Helwa ${ }^{1}$ \\ ${ }^{1}$ Genetics Department, Faculty of Agriculture, Menoufia University, Egypt \\ ${ }^{2}$ Institute of Genetic Engineering and Biotechnology Research, University of Sadat City, Egypt
}

\begin{abstract}
Species identification of isolates of Trichoderma from different locations of Nile delta of Egypt was performed and their cellulolytic activities were analyzed. On the basis of morphological characteristics, $75 \%$ of isolates were identified to species level and they were divided into four aggregate groups. Morphological characterization alone was insufficient to precisely identify Trichoderma species because they have relatively few morphological characters and limited variation that cause overlapping and misidentification of the isolates. Therefore, there was a necessity to use molecular technique to compensate for the limitations of morphological characterization. DNA sequencing of 5.8S-ITS region was carried out using specific primers ITS1 and ITS4. By comparing the sequences of the 5.8S-ITS region to the sequences deposited in GenBank using BLAST program all isolates can be identified to species level with homology percentage of at least $99 \%$. In addition, TrichOKEY search tool, was used to assess the reliability of Genbank and results were in $92 \%$ agreement with the BLAST results. Data indicated a narrow species diversity and there were two main species predominated namely; T. Iongibarchiatum and T. harzianum. Distribution of nucleotides as well as the $(G+C)$ content in ITS region of isolates indicated a wide range of interspecies variation. Finally, isolates were assessed for their total cellulase activities using a cellulose-azur method, for exoglucanases activity using Avicel method and for endoglucanases activity using carboxymethyl cellulose (CMC) and acid swollen cellulose methods. Consequently, eleven isolates were selected to be the best isolates among the 28 isolates used for cellulolytic ability.
\end{abstract}

Keywords: Morphological identification; Molecular identification; ITS region; Endoglucanases; Exoglucanases

\section{Introduction}

Trichoderma species are cosmopolitan fungi, frequently present in all types of soil, manure and decaying plant tissues. Their dominance in soil may be attributed to their diverse metabolic capability and aggressive competitive nature [1]. The economic importance of Trichoderma is due to their production of extracellular industrial enzymes, such as cellulolytic enzymes [2]. These enzymes are extensively used in industry such as degradation of cellulose materials which are used in textile and paper industry, in wastewater treatment and in biodegradation of plant lignocellulosic materials [3]. Cellulases are enzymatic complex, that comprises exo- $\beta$-1,4-glucanases (EC 3.2.1.91), endo- $\beta$-1,4-glucanases (EC 3.2.1.4) and $\beta-1,4$-glucanases (EC 3.2.1.21), that act synergistically in the hydrolysis of $\beta$-1,4-glycosidic bonds present in cellulose polymers for review see [4]. Therefore, many methods were developed to screen and select highly cellulases producing Trichoderma. The cellulose azure method is one of the choices where cellulose azure assay using dyed cellulose, a method of measuring primarily cellobiohydrolase activity by dye release [5]. The cellulose azure method is the most reliable qualitative assay for cellulolysis. This method also tests for simultaneous action of all cellulase enzymes. Degradation of cellulose results in the release of a bound dye, the vertical migration of which can be observed and the intensity of blue dye indicates the activity of cellulase [6]. Another assay was developed for screening of highly producing exoglucanase isolates using microcrystalline cellulose (Avicel) as substrate crystalline pure cellulose [7]. Also, cellulase can only degrade a specific substrate, therefore, screening of cellulase-producing Trichoderma can be performed on agar plates using a cellulosic substrate such as Avicel or carboxymethylcellulose (CMC) as carbon source for Trichoderma growth [8]. At the same time, quantitative assay of endoglucanase activity can be detected using carboxymethyl cellulose (CMC) by detection of clear zone around the colony using the Congo red stain [9].
Finally, another method for selection of hypercellulolytic Trichoderma spp. was using Petri plate with Walseth-cellulose as a sole source of Carbone [10].

Due to the diverse economical applications of Trichoderma, the correct species identification of Trichoderma is vital. Morphological characterization of Trichoderma isolates to species is currently based largely on many criteria such as conidial form, size, color and ornamentation, branching pattern, side branches, phialides and the formation of hyphal and elongation from conidiophores [11]. However, incorrect species identification using morphological characters is very common even for experts because of the high similarity of morphological characters [12]. However, recently many molecular methods and identification tools were developed, which are based on DNA sequence analysis. Therefore, it is now possible to identify every Trichoderma isolate to its species [13].

There are several molecular methods to characterize fungi species. Sequence analysis of the ITS region is the most famous method among molecular characterization methods. In eukaryotic cells, there are two internal transcribed spacers flanking the $5.8 \mathrm{~S}$ gene. The two spacers, together with the $5.8 \mathrm{~S}$ gene, are normally referred to as the ITS region [14]. The rRNA genes are universally conserved, while the ITS region

*Corresponding author: Abdelmegid I Fahmi, Department of Genetics, Faculty of Agriculture, Menoufiya University, Shebin El-Kom, Egypt, Tel: 2048222 170; Fax: 0020225769495; E-mail: abdelmageed.fahmy@agr.menofia.edu.eg

Received March 31, 2016; Accepted April 23, 2016; Published April 30, 2016

Citation: Fahmi Al, Eissa RA, El-Halfawi KA, Hamza HA, Helwa MS (2016) Identification of Trichoderma spp. by DNA Barcode and Screening for Cellulolytic Activity. J Microb Biochem Technol 8: 202-209. doi: 10.4172/1948-5948.1000286

Copyright: ( 2016 Fahmi Al, et al. This is an open-access article distributed under the terms of the Creative Commons Attribution License, which permits unrestricted use, distribution, and reproduction in any medium, provided the original author and source are credited. 
and intergenic spacer (IGS) are highly variable [15]. The ITS region is one the fastest evolving region and they may vary among species within a genus. Thus, the sequences of these regions can be used for identification of closely related species [16]. Sequence analysis of the ITS region have been used successfully to generate specific primers capable of differentiating closely related fungal species [17]. It has typically been most useful for molecular systematic study at species level, and even within species [18].

Finally, the use of ITS sequence analysis to identify an isolate at the species level involves submission of sequences to NCBI BLAST web site and identification of respective species on the basis of the degree of sequence similarity (e.g., >98\%). Also, the International Subcommission on Trichoderma and Hypocrea Taxonomy has developed a method namely TrichOKEY 2 . It is a program for molecular identification of Trichoderma on species levels based on an oligonucleotide ITS DNA BarCode (http://www.isth.info). Therefore, the objectives of the present study were: 1) species identification of some unknown isolates from different locations of Nile delta of Egypt and 2) documentation of their cellulolytic activity.

\section{Materials and Methods}

\section{Samples collection}

Different types of samples from soil, and decomposed organic matters, such as wheat straw and rice straw were collected from six governorates of Egypt. The samples were taken from a $15 \mathrm{~cm}$ depth and collected in sterile polyethylene bags, which were transported to the laboratory and stored at $4{ }^{\circ} \mathrm{C}$ until use [19].

\section{Isolation of Trichoderma sp.}

A serial dilution technique [20] was followed and a $10^{3}$ dilution of each sample was prepared. $250 \mu \mathrm{L}$ of each solution was pipetted onto a Potato Dextrose Agar (PDA) amended with $1 \mathrm{~g} / \mathrm{L}$ streptomycin (Merck) plate and incubated at $28^{\circ} \mathrm{C}$ for one week [21]. The culture plates were examined daily, individual colonies were isolated and uncommon colonies were reisolated onto a PDA plate [22]. Morphological characteristics were observed for identification and the plates were stored at $4^{\circ} \mathrm{C}$ [23]. In addition, four isolates were kindly provided by Prof. Dr Medhat Aldenary, Faculty of Agriculture, Tanta University and three isolates from our laboratory were included in this investigation.

\section{Identification of Trichoderma isolates}

\section{Morphological identification}

Two techniques, visual observation on petri dishes and micromorphological studies in slide culture, were adopted for identification of Trichoderma species. For visual observation, the isolates were grown on PDA agar for 3-5 days. The mode of mycelia growth, color, odor and changes of medium color for each isolate were examined every day. For micromorphological studies, a slide culture technique was used. Examination of the shape, size, arrangement and development of conidiophores or phialides provided a tentative identification of Trichoderma spp. [24]. Further verified and confirmed identification was performed at Plant Pathology Research Institute, Agricultural Research Center, Giza, Egypt.

\section{Molecular identification}

Molecular identification with sequences analysis of the internal transcribed spacer (ITS) 1 and 4 of ribosomal DNA (rDNA) was carried.

a) DNA extraction and purification: Isolates were inoculated onto
Potato Dextrose Broth and maintained on a rotary shaker at $25^{\circ} \mathrm{C}$ for five days. Fungal cells were collected by filtration and homogenized in liquid nitrogen. Genomic DNA was extracted from mycelia of Trichoderma isolates using EZ-10 SPIN COLUMN GENOMIC DNA MINIPREPS KIT (BIO BASIC INC.) according to the manufacturer's instructions. Both the purity and quantity of DNA were checked by agarose gel electrophoresis.

b) PCR was used to amplify the internal transcribed spacer regions 1 and 4 (ITS1 and 4) of the rRNA gene cluster using the following primer pair amplified as designed by Hermosa et al., [25] with modifications (Table 1).

PCR amplifications were performed in a total volume of $50 \mu \mathrm{l}$ by mixing $200 \mathrm{ng}$ of the template DNA with $0.6 \mu \mathrm{M}$ of each primer, $25 \mu \mathrm{l}$ of $2 \mathrm{x}$ MyTaq ${ }^{\mathrm{TM}}$ Red Mix. DNA thermal cycles was used with the following PCR profile: an initial denaturation of $5 \mathrm{~min}$ at $95^{\circ} \mathrm{C}$, followed by 35 cycles $\left(1.0 \mathrm{~min}\right.$ at $94^{\circ} \mathrm{C}, 2 \mathrm{~min}$ at $55^{\circ} \mathrm{C}$ and $2 \mathrm{~min}$ at $72{ }^{\circ} \mathrm{C}$ ) with a final extension of $5 \mathrm{~min}$ at $72^{\circ} \mathrm{C}$. Aliquots $(5 \mu \mathrm{l})$ were analyzed by electrophoresis in $1.2 \%$ (wt/vol) agarose gel in $1 \times$ TBE buffer $(0.045 \mathrm{M}$ Tris-borate and 1 mM EDTA, $\mathrm{pH}$ 8.2) and stained with ethidium bromide (final concentration $0.2 \mathrm{mg} \mathrm{ml}^{-1}$ ).

c) DNA sequencing: purified and sequencing of the PCR products (amplified DNA) were performed by Macrogen Inc. (South Korea) using state-of-the-art robotics and instrumentation.

d) Sequence submission: Sequences were submitted to GenBank through Bankit (a World Wide Web sequence submission server available at NCBI home page). The sequences are available on line (http://www.ncbi.nlm.nih.gov) and can be located by accession numbers: KT964120, KT964121, KT964122, KT964123, KT964124, KT964125, KT964126, KT964127, KT964128, KT964129, KT964130, KT964131, KT964132, KT964133, КT964134, КT964135, КT964136, КT964137, KT964138, KT964139, КT964141, KT964143, КT964144, KT964140, KT964142, KT964145, KT964146, and KT964147

e) Sequence Analysis: The sequences of ITS1-5.8S-ITS4 region of all isolates were analyzed using Molecular Evolutionary Genetics Analysis (MEGA4 version 5.10.). The sequencing data were compared against the Gene Bank database (http:// www.ncbi.nlm.nih.gov/BLAST/), where a nucleotide blast program was chosen to identify the homology between the PCR fragments and the sequences on the Gene Bank database. Besides, the 5.8S-ITS sequences were compared to a specific database for Trichoderma using TrichOKEY 2 program, which available online from the International Subcommission on Trichoderma and Hypocrea Taxonomy (ISTH, www.isth.info) [13].

\section{Screening of Trichoderma isolates for cellulolytic activity}

Total cellulases (Cellulose azure agar): This method carried

\begin{tabular}{|c|c|c|c|}
\hline Primer Name & Sequence( 5'- 3') & Mer & GC\% \\
\hline ITS-1 & $\begin{array}{c}5^{\prime} \text { - TCC GTA GGT GAA } \\
\text { CCT GCG G - 3' }\end{array}$ & 19 & 63.16 \\
\hline ITS-4 & $\begin{array}{c}5^{\prime} \text { - TCC TCC GCT TAT } \\
\text { TGA TAT GC - 3' }\end{array}$ & 20 & 45 \\
\hline
\end{tabular}

Table 1: Molecular identification with sequences analysis of the internal transcribed spacer. 
out as described by Pointing SB et al., [6]. Cellulolysis was assessed by monitoring release of azure dye from cellulose-dye complex and diffusion into clear agar not containing cellulose-azure. As follow: Cellulolysis basal medium (CBM) $0.5 \%(\mathrm{w} / \mathrm{v})$ Diammonium tartrate $(\mathrm{C} 4 \mathrm{HI} 2 \mathrm{~N} 206)$ ), $0.01 \%(\mathrm{w} / \mathrm{v})$ yeast extract , $0.05 \%(\mathrm{w} / \mathrm{v}) \mathrm{MgSO}_{4} \cdot 7 \mathrm{H}_{2} \mathrm{O}$, 0. $1 \%(\mathrm{w} / \mathrm{v}) \quad \mathrm{KH}_{2} \mathrm{PO}_{4}, 0.001 \%(\mathrm{w} / \mathrm{v}) \quad \mathrm{CaCl}_{2} \cdot 2 \mathrm{H}_{2} \mathrm{O}$ supplemented with $1.6 \% \mathrm{w} / \mathrm{v}$ agar was transferred to $25 \mathrm{~mL}$ glass culture bottles, autoclaved, allowed to solidify. Then carefully aliquot of $1 \mathrm{ml}$ of CBM medium supplemented with $1 \% \mathrm{w} / \mathrm{v}$ cellulose azure (azure I dye, sigma C.I.52010) aseptically was loaded on the surface of the solidified agar as an overlay. Media were inoculated with $5 \times 10^{5}$ spores of Trichoderma isolates and incubated at $28^{\circ} \mathrm{C}$ in darkness. Migration of dye into the clear lower layer indicated the presence of Cellulases. Cellulolysis was assessed by monitoring release of azure dye from cellulose-dye complex and diffusion into clear agar. The relative cellolytic activity of each isolate was scored by comparing the intensity of blue color of the medium with standard blue color scale of 1 to 10 (maximum) over an incubation period of 15 days [26].

\section{Exoglucanases}

A method by Bose RG et al., with some modifications was carried out to screen for high cellulase-producing isolates [27]. The basic medium consisted of a Mandel's mineral solution supplemented with trace elements and 2\% agar [28]. Avicel PH-101 NF was used as the sole source of carbon at a concentration of $1 \% .0 .01 \%$ Triton-X 100 was added to limit the colony size and to facilitate the screening of isolates. The cellulose agar plates were seeded with $5 \times 10^{5}$ spores in $20 \mu \mathrm{l}$ and incubated at $28^{\circ} \mathrm{C}$ for 21 days until clear zones around fungal colonies were observed. Then the diameter of the clear zone was measured.

\section{Endoglucanases}

Dye staining of carboxymethylcellulose agar (CMC agar): The cellulolytic activity of fungal strains was determined by their ability to grow and form cleared zones around colonies on Mandel's agar medium (MAM) supplemented with $0.5 \% \mathrm{w} / \mathrm{v}$ low viscosity carboxymethyl cellulose (CMC) [29]. The medium was autoclaved, dispensed into Petri dishes, allowed to solidify and inoculated with $5 \times 10^{5}$ spores in $20 \mu \mathrm{l}$ Trichoderma isolates and incubated at $28^{\circ} \mathrm{C}$. After growth for 5 days, the plates were flooded with $1 \%$ aqueous Congo red and allowed to stain for 15 minutes. The stain was washed off from the agar surface with distilled water and the plates were then flooded with $1 \mathrm{M} \mathrm{NaCl}$ to destain for 15 minutes. The $\mathrm{NaCl}$ solution was then removed. CMC degradation around the colonies appears as a yellow-opaque area against a red color for undegraded CMC. The diameter of the clear zone was measured [6].

\section{Walseth cellulose Plate-clearing assay}

A method by Khiyami et al., with some modifications was carried out to screen for high cellulase-producing isolates [26]. The basic medium consisted of a Mandel's mineral solution supplemented with trace elements and 2\% agar. Phosphoric acid-swollen cellulose (Walseth cellulose) was used as the sole source of carbon at a concentration of 1\%. $0.01 \%$ Triton-X 100 was added to limit the colony size and to facilitate the screening of isolates [30]. The plates were seeded with $5 \times 10^{5}$ spores in $20 \mu \mathrm{l}$ and incubated at $28^{\circ} \mathrm{C}$ for 6 days until clear zones around fungal colonies were observed. Then the diameter of the clear zone was measured.

\section{Statistical analysis}

One-way ANOVA followed by Duncan's multiple range test
(DMRT) was used to assess the statistical significance of changes in all indices with the level of significant difference set at $p<0.05$. Statistical analysis software (SPSS 16.0.0 release; SPSS Inc., Chicago, IL) was used for all analyses.

\section{Results}

A total of 28 fungal isolates were analyzed in this investigation. 21 isolates were collected samples from six governorates of Nile delta of Egypt namely; Menufia, Gharbia, Kafr el Sheikh, Sharqia, Dakahlia and Ismalia (Figure 1). In addition, four isolates were given from Tanta university collection and three isolates were from our laboratory collection. Preliminary screening was carried out for all isolates which showed that these fungal isolates were Trichoderma species. The type of samples and isolate codes were shown in Table 2.

Morphological identification of the 28 Trichoderma isolates was performed and resulted in identification of all 28 isolates as Trichoderma genus (Table 3). However, as for species identification, seven isolates were not identified to species level (25\%). The rest of the isolates (75\%) were species identified and they divided into four groups. Seven isolates were identified as Trichoderma harzianum, six isolates as Trichoderma hamatum, five as Trichoderma viride and three as Trichoderma koningii.

As for molecular identification, genomic DNA of all Trichoderma isolates was extracted. PCR Amplification of 5.8S-ITS Region was conducted using specific primers ITS1 and ITS4. 5.8S-ITS DNA fragments were amplified from all Trichoderma isolates and PCR products were sequenced. Then, BLAST program was used to determine the species identity of Trichoderma isolates. The BLAST results were presented in Table 4. According to the BLAST results, 15 isolates were identified as T. longibarchiatum (54\%) and seven isolates were identified as T. harzianum (25\%), while five isolates were identified as T. album, T. virens, T.viride, T. asperellum and T. saturnisporum. Only, one isolate MNF-MSH-Trich 23 could not be identified to species level. Also, TrichOKEY search was also used to assess the reliability of BLAST results. Three isolates were not identified to species level namely, MNF-MSH-Trich4, MNF-MSH-Trich22, MNF-MSH-Trich23

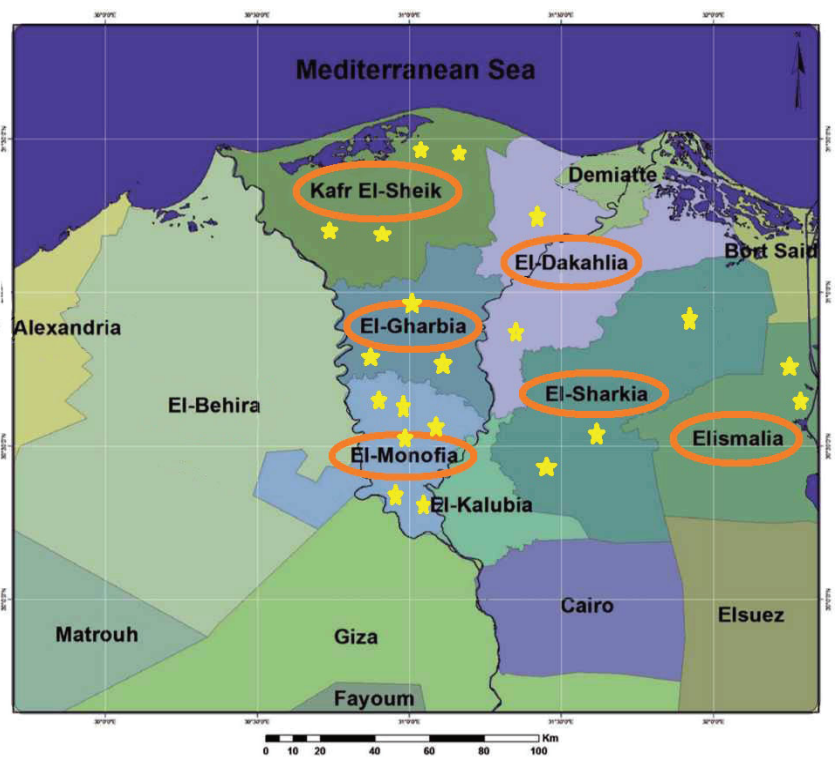

Figure 1: Map of the isolation sites in six governorates in the North Nile Delta in Egypt. 
Citation: Fahmi Al, Eissa RA, El-Halfawi KA, Hamza HA, Helwa MS (2016) Identification of Trichoderma spp. by DNA Barcode and Screening for Cellulolytic Activity. J Microb Biochem Technol 8: 202-209. doi: 10.4172/1948-5948.1000286

\begin{tabular}{|l|c|c|}
\hline tSample type & Source & Isolates code \\
\hline Decomposed Wheat straw & Menoufia & MNF-MSH-Trich1 \\
\hline Field soil & Menoufia & MNF-MSH-Trich2 \\
\hline Decomposed rice straw & Gharbiya & MNF-MSH-Trich3 \\
\hline Decomposed rice straw & Kafr el Sheikh & MNF-MSH-Trich4 \\
\hline Field soil & Sharqiya & MNF-MSH-Trich 5 \\
\hline- & Genetics department collection & MNF-MSH-Trich6 \\
\hline Decomposed rice straw & Sharqiya & MNF-MSH-Trich7 \\
\hline Decomposed Wheat straw & Menoufia & MNF-MSH-Trich8 \\
\hline Decomposed rice straw & Gharbiya & MNF-MSH-Trich9 \\
\hline Decomposed rice straw & Kafr el Sheikh & MNF-MSH-Trich10 \\
\hline Decomposed tree leaves & Menoufia & MNF-MSH-Trich11 \\
\hline- & Genetics department collection & MNF-MSH-Trich12 \\
\hline- & Genetics department collection & MNF-MSH-Trich13 \\
\hline Decomposed rice straw & Dakahlia & MNF-MSH-Trich14 \\
\hline Decomposed rice straw & Dakahlia & MNF-MSH-Trich15 \\
\hline Decomposed tree leaves & Ismaillia & MNF-MSH-Trich16 \\
\hline- & Tanta university collection & MNF-MSH-Trich17 \\
\hline- & Tanta university collection & MNF-MSH-Trich18 \\
\hline- & Tanta university collection & MNF-MSH-Trich19 \\
\hline - & Tanta university collection & MNF-MSH-Trich20 \\
\hline Field soil & Kafr el Sheikh & MNF-MSH-Trich21 \\
\hline Decomposed rice straw & Kafr el Sheikh & MNF-MSH-Trich22 \\
\hline Decomposed Wheat straw & Sharqiya & MNF-MSH-Trich23 \\
\hline Garden soil & Menoufia & MNF-MSH-Trich24 \\
\hline Decomposed rice straw & Gharbiya & MNF-MSH-Trich25 \\
\hline Garden soil & Ismaillia & MNF-MSH-Trich26 \\
\hline Decomposed Wheat straw & Menoufia & MNF-MSH-Trich27 \\
\hline Decomposed Wheat straw & Menoufia & MNF-MSH-Trich28 \\
\hline & &
\end{tabular}

\begin{tabular}{|c|c|}
\hline Species name & Isolates code \\
\hline Trichoderma harzianum & MNF-MSH-Trich1 \\
\hline Trichoderma viride & MNF-MSH-Trich2 \\
\hline Trichoderma hamatum & MNF-MSH-Trich3 \\
\hline Trichoderma Sp. & MNF-MSH-Trich4 \\
\hline Trichoderma hamatum & MNF-MSH-Trich 5 \\
\hline Trichoderma hamatum & MNF-MSH-Trich6 \\
\hline Trichoderma koningii & MNF-MSH-Trich7 \\
\hline Trichoderma Sp. & MNF-MSH-Trich8 \\
\hline Trichoderma hamatum & MNF-MSH-Trich9 \\
\hline Trichoderma koningii & MNF-MSH-Trich10 \\
\hline Trichoderma harzianum & MNF-MSH-Trich11 \\
\hline Trichoderma harzianum & MNF-MSH-Trich12 \\
\hline Trichoderma Sp. & MNF-MSH-Trich13 \\
\hline Trichoderma viride & MNF-MSH-Trich14 \\
\hline Trichoderma viride & MNF-MSH-Trich15 \\
\hline Trichoderma viride & MNF-MSH-Trich16 \\
\hline Trichoderma viride & MNF-MSH-Trich17 \\
\hline Trichoderma harzianum & MNF-MSH-Trich18 \\
\hline Trichoderma harzianum & MNF-MSH-Trich19 \\
\hline Trichoderma koningii & MNF-MSH-Trich20 \\
\hline Trichoderma Sp. & MNF-MSH-Trich21 \\
\hline Trichoderma harzianum & MNF-MSH-Trich22 \\
\hline Trichoderma Sp. & MNF-MSH-Trich23 \\
\hline Trichoderma harzianum & MNF-MSH-Trich24 \\
\hline Trichoderma Sp. & MNF-MSH-Trich 25 \\
\hline Trichoderma Sp. & MNF-MSH-Trich26 \\
\hline Trichoderma hamatum & MNF-MSH-Trich27 \\
\hline Trichoderma hamatum & MNF-MSH-Trich28 \\
\hline
\end{tabular}

Table 2: Trichoderma isolate codes, isolate origins and types of sample used in this study.

and MNF-MSH-Trich27. Similarly, MNF-MSH-Trich23 isolate was only identified until genus level. However, 24 isolates were identified to species level (Table 5). They were divided into two main groups namely; T. longibarchiatum (14 isolates) and T. harzianum (seven isolates). In addition to three individual groups namely; T. virens, T. asperellum and T. koningiopsis. Based on the TrichOKEY results obtained, 22 out of $44(92 \%)$ isolates were in agreement with the results obtained from GenBank database. The disagreement was in MNF-MSH-Trich 15 and MNF-MSH-Trich19 isolates.

Finally, Table 6 showed the distribution of nucleotides as well as the guanosine + cytosine $(\mathrm{G}+\mathrm{C})$ content in ITS1+5.8S+ITS2 complete sequences. A total length of ITS1-5.8S-ITS2 sequence region ranged from $546 \mathrm{bp}$ to $1028 \mathrm{bp}$ in all accessions. While, the $\mathrm{G}+\mathrm{C}$ content ranged from $24.2 \%$ to $68.8 \%$.

Total cellulase, endoglucanase, and exoglucanase activities were determined using cellulose azure agar method, carboxymethyl cellulose (CMC), and microcrystalline cellulose (SIG) as substrates, respectively, according to standard conditions described by [5] (Table 7).

First isolates were assessed for their total cellulase activities using Dye diffusion from a cellulose-dye complex (cellulose azure agar) method. Ten isolates recorded 10 in this scale means that they have good cellulolysis ability (Table 7). 12 isolates recorded ten namely; MNFMSH-Trich2, MNF-MSH-Trich5, MNF-MSH-Trich7, MNF-MSHTrich8, MNF-MSH-Trich9, MNF-MSH-Trich10, MNF-MSH-Trich14, MNF-MSH-Trich19, MNF-MSH-Trich21, MNF-MSH-Trich22, MNFMSH-Trich26 and MNF-MSH-Trich27. Two isolates recorded seven

Table 3: The identities of Trichoderma isolates identified morphologically used in this study.

MNF-MSH-Trich16 and MNF-MSH-Trich17. The rest of the isolates recorded between eight and nine.

Secondly Avicel is used for measuring exoglucanase activity because it has a low degree of polymerisation of cellulose and it is relatively inaccessible to attack by endoglucanases despite some amorphous regions. Six isolates showed highly significant Avicellulases activity namely; MNF-MSH-Trich1, MNF-MSH-Trich7, MNF-MSH-Trich8, MNF-MSH-Trich14, MNF-MSH-Trich22 and MNF-MSH-Trich26 (Table 7).

Thirdly, Trichoderma isolates were identified for their endoglucanase activities on plate clearing assay by using carboxymethyl cellulose (CMC) and Congo red dye and by the formation of clear zone diameter. Based on measurements, six isolates gave clear zones of cellulase activity having diameter significantly larger than other isolates namely; MNF-MSH-Trich5, MNF-MSH-Trich7, MNF-MSH-Trich9, MNF-MSH-Trich10, MNF-MSH-Trich14 and MNF-MSH-Trich21. Carboxymethylcellulose (CMC) is a substrate for endoglucanase and so can be used as a test for endoglucanase and $\beta$-glucosidase activity (Table 7).

Another assay was conducted for endonuclease activities identification by using plate clearing assay of acid swollen cellulose as a substrate. Recording clearance of cellulose within the growth medium can be difficult to assess, particularly with dense or dark hyphal growth (Table 7). Six isolates showed high activities namely; MNF-MSHTrich1, MNF-MSH-Trich8, MNF-MSH-Trich14, MNF-MSH-Trich22, MNF-MSH-Trich26 and MNF-MSH-Trich27. 
Citation: Fahmi Al, Eissa RA, El-Halfawi KA, Hamza HA, Helwa MS (2016) Identification of Trichoderma spp. by DNA Barcode and Screening for Cellulolytic Activity. J Microb Biochem Technol 8: 202-209. doi: 10.4172/1948-5948.1000286

\begin{tabular}{|c|c|c|c|c|c|}
\hline $\begin{array}{l}\text { Species name } \\
\text { (Anamorph) }\end{array}$ & $\begin{array}{c}\text { NCBI GenBank } \\
\text { accession } \\
\text { number }\end{array}$ & $\begin{array}{c}\text { Max identification } \\
\%\end{array}$ & E value & Alignments Description & Isolates code \\
\hline T. harzianum & KT964120 & 99 & 0.0 & Trichoderma harzianum KC551815.1 & MNF-MSH-Trich1 \\
\hline T. harzianum & KT964121 & 98 & 0.0 & Hypocrea lixii HQ149775.1 & MNF-MSH-Trich2 \\
\hline T. longibrachiatum & KT964122 & 99 & 0.0 & Trichoderma longibrachiatum JX908726.1 & MNF-MSH-Trich3 \\
\hline T. harzianum & KT964123 & 94 & 0.0 & Hypocrea lixii EF596966.1 & MNF-MSH-Trich4 \\
\hline T. harzianum & KT964124 & 93 & 0.0 & Hypocrea lixii JX173856.1 & MNF-MSH-Trich5 \\
\hline T. longibrachiatum & KT964125 & 99 & 0.0 & Trichoderma longibrachiatum LN713973.1 & MNF-MSH-Trich6 \\
\hline T. longibrachiatum & KT964126 & 98 & 0.0 & Trichoderma longibrachiatum JX173872.1 & MNF-MSH-Trich7 \\
\hline T. longibrachiatum & KT964127 & 99 & 0.0 & Trichoderma longibrachiatum LN713973.1 & MNF-MSH-Trich8 \\
\hline T. longibrachiatum & KT964128 & 98 & 0.0 & Trichoderma longibrachiatum KP256797.1 & MNF-MSH-Trich9 \\
\hline T. longibrachiatum & KT964129 & 99 & 0.0 & Trichoderma longibrachiatum KM103341.1 & MNF-MSH-Trich10 \\
\hline T. longibrachiatum & KT964130 & 99 & 0.0 & Trichoderma longibrachiatum JX173872.1 & MNF-MSH-Trich11 \\
\hline T. longibrachiatum & KT964131 & 100 & 0.0 & Trichoderma longibrachiatum KP268994.1 & MNF-MSH-Trich12 \\
\hline T. longibrachiatum & KT964132 & 99 & 0.0 & Trichoderma longibrachiatum JX908727.1 & MNF-MSH-Trich13 \\
\hline T. harzianum & KT964133 & 100 & 0.0 & Trichoderma harzianum KT027929.1 & MNF-MSH-Trich14 \\
\hline T. album & KT964134 & 97 & 0.0 & Trichoderma album JF304318.1 & MNF-MSH-Trich15 \\
\hline T. longibrachiatum & KT964135 & 99 & 0.0 & Trichoderma longibrachiatum KM103341.1 & MNF-MSH-Trich16 \\
\hline T. virens & KT964136 & 96 & 0.0 & Trichoderma virens JX908730.1 & MNF-MSH-Trich17 \\
\hline T. asperellum & KT964137 & 97 & 0.0 & Trichoderma asperellum GU589849.1 & MNF-MSH-Trich18 \\
\hline T. viride & KT964138 & 99 & 0.0 & Hypocrea rufa JQ040401.1 & MNF-MSH-Trich19 \\
\hline T. longibrachiatum & KT964139 & 99 & 0.0 & Trichoderma longibrachiatum KF986656.1 & MNF-MSH-Trich20 \\
\hline T. longibrachiatum & KT964141 & 99 & 0.0 & Trichoderma longibrachiatum GU055306.1 & MNF-MSH-Trich21 \\
\hline T. saturnisporum & KT964143 & 99 & 0.0 & Trichoderma saturnisporum LM653121.1 & MNF-MSH-Trich22 \\
\hline- & KT964144 & - & - & - & MNF-MSH-Trich23 \\
\hline T. longibrachiatum & KT964140 & 95 & 0.0 & Trichoderma longibrachiatum JN039070.1 & MNF-MSH-Trich24 \\
\hline T. harzianum & KT964142 & 99 & 0.0 & Hypocrea lixii GU589848.1 & MNF-MSH-Trich25 \\
\hline T. harzianum & KT964145 & 99 & 0.0 & Trichoderma harzianum KC551815.1 & MNF-MSH-Trich26 \\
\hline T. longibrachiatum & KT964146 & 95 & 0.0 & Trichoderma longibrachiatum KM203582.1 & MNF-MSH-Trich27 \\
\hline T. longibrachiatum & KT964147 & 92 & 0.0 & Trichoderma longibrachiatum KJ561614.1 & MNF-MSH-Trich28 \\
\hline
\end{tabular}

Table 4: Molecular identification of Trichoderma isolates used in this study by NCBI BLASTN.

\section{Discussion}

The present study basically is a domestic assessment of Trichoderma representing six Egyptian governorates. Morphological characterization was conventionally used in the identification of Trichoderma species, and it remains as a potential method to identify Trichoderma species [31]. According to this investigation results, morphological and cultural characteristics could not distinguish Trichoderma isolates up to the species level efficiently. Similarly, most of the researchers were facing difficulty with regard to the identification of the Trichoderma species owing to the higher level of structural similarities [32]. Therefore, information from morphological study alone is insufficient to precisely identify a Trichoderma species because Trichoderma species have relatively few morphological characters and limited variation that may cause overlapping and misidentification of the isolates [31]. Besides that, morphological characteristics are influenced by culture conditions [33]. Therefore, there is a necessity to use molecular technique to compensate for the limitations of morphological characterization.

In this study, DNA sequencing of the 5.8S-ITS region was carried out using specific primers ITS1 and ITS4. The ITS region is one of the most reliable loci for the identification of a strain at the species level [34]. By comparing the sequences of the 5.8S-ITS region to the sequences deposited in GenBank, all of the Trichoderma isolates except MNF-MSH-Trich 23 can be identified to species level with homology percentage of at least $99 \%$. However, Druzhinina et al., mentioned that GenBank database contain many sequences of Trichoderma isolates which may have been incorrectly identified and occurred under a false name [35]. Hence, TrichOKEY search tool, a program that specifically compare ITS1 and ITS2 sequences to a specific database for Trichoderma generated from only vouchered sequences were used to assess the reliability of BLAST results. TrichOKEY was used by many literatures and resulted in successful identification of Trichoderma isolates [31]. From the TrichOKEY results obtained all isolates except isolate MNF-MSH-Trich 23 were identified. The results were in $92 \%$ agreement with the BLAST results. Isolate MNF-MSHTrich23, however, was identified as an unknown Trichoderma species. Also, morphological data of MNF-MSH-Trich23 was insufficient to be identified. The main difference between the two data bases results were in two isolates MNF-MSH-Trich 15 and MNF-MSH-Trich 19. Results of this investigation confirmed the same difficulty facing other researchers where the morphological characterization is not reliable. The morphological identification agreed with molecular identification in only one isolate MNF-MSH-Trich1. It was concluded that, the morphological characterization is not reliable for identification of the isolates and oligonucleotide barcode is a powerful tool for the identification of Trichoderma species and should be useful as an alternative or as a complement to morphological methods. Therefore, the molecular data of ITS sequence is more trusted in characterization and identification of isolates under study. Consequently, according to molecular findings there were two main species predominated in these isolates. T. longibarchiatum consisted about $50 \%$ of the isolates and $T$. harzianum consisted about $25 \%$ of the isolates. Most of these two species came from the isolates of the collected materials. This data indicted a 
Citation: Fahmi Al, Eissa RA, El-Halfawi KA, Hamza HA, Helwa MS (2016) Identification of Trichoderma spp. by DNA Barcode and Screening for Cellulolytic Activity. J Microb Biochem Technol 8: 202-209. doi: 10.4172/1948-5948.1000286

\begin{tabular}{|c|c|c|c|c|}
\hline $\begin{array}{l}\text { Identification } \\
\text { reliability }\end{array}$ & Species identification & Clade & Section & Isolates code \\
\hline high & Trichoderma harzianum & Harzianum & Pachybasium & MNF-MSH-Trich1 \\
\hline high & Trichoderma harzianum & Harzianum & Pachybasium & MNF-MSH-Trich2 \\
\hline high & Trichoderma longibrachiatum & Longibrachiatum & Longibrahiatum & MNF-MSH-Trich3 \\
\hline- & \multicolumn{3}{|c|}{ The query sequence is incomplete } & MNF-MSH-Trich4 \\
\hline high & Trichoderma harzianum & Harzianum & Pachybasium & MNF-MSH-Trich5 \\
\hline high & Trichoderma longibrachiatum & Longibrachiatum & Longibrahiatum & MNF-MSH-Trich6 \\
\hline high & Trichoderma longibrachiatum & Longibrachiatum & Longibrahiatum & MNF-MSH-Trich7 \\
\hline high & Trichoderma longibrachiatum & Longibrachiatum & Longibrahiatum & MNF-MSH-Trich8 \\
\hline high & Trichoderma longibrachiatum & Longibrachiatum & Longibrahiatum & MNF-MSH-Trich9 \\
\hline high & Trichoderma longibrachiatum & Longibrachiatum & Longibrahiatum & MNF-MSH-Trich10 \\
\hline high & Trichoderma longibrachiatum & Longibrachiatum & Longibrahiatum & MNF-MSH-Trich11 \\
\hline high & Trichoderma longibrachiatum & Longibrachiatum & Longibrahiatum & MNF-MSH-Trich12 \\
\hline high & Trichoderma longibrachiatum & Longibrachiatum & Longibrahiatum & MNF-MSH-Trich13 \\
\hline high & Trichoderma harzianum & Harzianum & Pachybasium & MNF-MSH-Trich14 \\
\hline high & Trichoderma harzianum & Harzianum & Pachybasium & MNF-MSH-Trich15 \\
\hline high & Trichoderma longibrachiatum & Longibrachiatum & Longibrahiatum & MNF-MSH-Trich16 \\
\hline high & Trichoderma virens & Virens & Pachybasium & MNF-MSH-Trich17 \\
\hline high & Trichoderma asperellum & $\begin{array}{l}\text { Pachybasium "A" or } \\
\text { Hamatum }\end{array}$ & Trichoderma & MNF-MSH-Trich18 \\
\hline high & Trichoderma koningiopsis & Viride & Trichoderma & \multirow{3}{*}{ MNF-MSH-Trich 19} \\
\hline standard & Trichoderma ovalisporum & Viride & Trichoderma & \\
\hline high & Trichoderma asperellum & $\begin{array}{l}\text { Pachybasium "A" or } \\
\text { Hamatum }\end{array}$ & Trichoderma & \\
\hline high & Trichoderma longibrachiatum & Longibrachiatum & Longibrahiatum & MNF-MSH-Trich20 \\
\hline high & Trichoderma longibrachiatum & Longibrachiatum & Longibrahiatum & MNF-MSH-Trich21 \\
\hline low & Trichoderma sp. MA 3642 & Longibrachiatum & Longibrahiatum & MNF-MSH-Trich22 \\
\hline \multicolumn{4}{|c|}{$\begin{array}{l}\text { The sequence was not identified. ITS1 and ITS2 regions of Hypocrea/Trichoderma were not detected. The 5.8S RNA gene is found } \\
\text { which is not diagnostic for species identification. }\end{array}$} & MNF-MSH-Trich23 \\
\hline high & Trichoderma longibrachiatum & Longibrachiatum & Longibrahiatum & MNF-MSH-Trich24 \\
\hline high & Trichoderma harzianum & Harzianum & Pachybasium & MNF-MSH-Trich25 \\
\hline high & Trichoderma harzianum & Harzianum & Pachybasium & MNF-MSH-Trich26 \\
\hline \multicolumn{4}{|c|}{ The query sequence is incomplete } & MNF-MSH-Trich27 \\
\hline high & Trichoderma longibrachiatum & Longibrachiatum & Longibrahiatum & MNF-MSH-Trich28 \\
\hline
\end{tabular}

Table 5: Molecular identification of Trichoderma isolates used in this study by TrichOKEY2.

narrow species diversity of Trichoderma isolates in the middle Delta area of Egypt. Gherbawy et al., found only one species T. harzianum in the area of Delta of Egypt [36]. Other results from south of Egypt indicated that the two species T. harzianum and T. longibarchiatum were present [37]. The predominant T. longibrachiatum is the youngest clade of Trichoderma evolutionarily [38]. Also, it is a soil fungus which is found all over the world but mainly in warmer climates [39]. The second predominant species T. harzianum is the most commonly reported species in the genus, occurring in diverse ecosystems and ecological niches [40]. Therefore, this low degree of diversity may occur due to specific biotic or abiotic factors such as plant species, microbial competition, soil physical and chemical properties and application of pesticides or fertilizers in the geographical region [4].

In addition, the interspecies identification of the species from different isolates was carried out in this study. The results showed that although, the rDNA ITS sequence was very conservative, there were variation on sequence and length among different isolates, and there was a genetic differentiation in a various degrees. Consequently, variation among individuals of the same species was noticed. For instance within T. longibarchiatum the GC\% varied from $42.6 \%$ to $68.8 \%$, while the ITS length was between 561 and 888 nucleotides. Also, within T. harzianum variation was in length between 546 and 1028 nucleotides and in GC\% was between $49.6 \%$ and $55.7 \%$. This indicated a wide range of interspecies variatins which is consistent with the idea of haplotype presence among species [4].

As mentioned before, Trichoderma sp. exhibited the highest cellulose activity and consistency in producing cellulase when compared with other microorganisms [41]. Total cellulase activity was measured using cellulose azure agar method. It is highly recommended as it is the most reliable qualitative assay for cellulolysis [42]. The experiment for cellulose azure method was conducted for 15 days, the period of time will allow Trichoderma to degrade link of azure and cellulose. Fadel et al., reported that each microorganism have the different incubation time to do the enzymatic reaction to the substrate [43]. Further analysis was conducted to differentiate isolates into two categories either highly endonucleases or exonuleases producing isolates. Avicel has been used for measuring exoglucanase activities that cleave the accessible ends of cellulose modules to liberate glucose and cellobiose [44]. To identify highly producing endoglucanases producing isolates two methods were carried out namely; CMC and Walseth cellulose plate assay. CMC is chemically modified and used to resemble the cellulose and Congo red can only colorize the cellulose and the area that is decolorized indicated the endoglucanases enzyme activity [45]. Hydrolysis of cellulose, especially the endoglucanases enzyme, is crucial, as it initiates the next 
Citation: Fahmi Al, Eissa RA, El-Halfawi KA, Hamza HA, Helwa MS (2016) Identification of Trichoderma spp. by DNA Barcode and Screening for Cellulolytic Activity. J Microb Biochem Technol 8: 202-209. doi: 10.4172/1948-5948.1000286

\begin{tabular}{|c|c|c|c|c|c|c|}
\hline Isolate code & $\mathrm{T} \%$ & C $\%$ & A $\%$ & G \% & $\begin{array}{c}\mathrm{G}+\mathrm{C} \\
(\mathrm{mol} \%)\end{array}$ & $\begin{array}{l}\text { Length (nt) } \\
\text { analyzed } \\
\text { dataset }\end{array}$ \\
\hline MNF-MSH-Trich 1 & 26.7 & 23.6 & 23.7 & 26.0 & 49.6 & 1028.0 \\
\hline MNF-MSH-Trich2 & 22.0 & 24.8 & 24.4 & 28.8 & 53.6 & 833.0 \\
\hline MNF-MSH-Trich3 & 21.2 & 24.1 & 26.8 & 27.9 & 52.0 & 806.0 \\
\hline MNF-MSH-Trich4 & 25.2 & 32.7 & 19.7 & 22.4 & 55.1 & 630.0 \\
\hline MNF-MSH-Trich 5 & 24.8 & 25.4 & 25.5 & 24.3 & 49.7 & 678.0 \\
\hline MNF-MSH-Trich6 & 22.4 & 31.0 & 20.6 & 26.0 & 57.0 & 616.0 \\
\hline MNF-MSH-Trich7 & 29.0 & 25.3 & 22.3 & 23.4 & 48.7 & 766.0 \\
\hline MNF-MSH-Trich8 & 25.1 & 25.9 & 23.4 & 25.6 & 51.5 & 710.0 \\
\hline MNF-MSH-Trich9 & 21.6 & 24.1 & 31.4 & 22.9 & 47.0 & 730.0 \\
\hline MNF-MSH-Trich10 & 14.8 & 21.9 & 16.5 & 46.9 & 68.8 & 778.0 \\
\hline MNF-MSH-Trich11 & 29.6 & 32.6 & 19.0 & 18.8 & 51.4 & 709.0 \\
\hline MNF-MSH-Trich12 & 22.3 & 31.7 & 20.1 & 25.8 & 57.5 & 561.0 \\
\hline MNF-MSH-Trich13 & 26.3 & 27.2 & 21.6 & 24.9 & 52.1 & 662.0 \\
\hline MNF-MSH-Trich14 & 22.7 & 29.7 & 21.6 & 26.0 & 55.7 & 546.0 \\
\hline MNF-MSH-Trich15 & 25.4 & 25.4 & 20.4 & 28.8 & 54.2 & 760.0 \\
\hline MNF-MSH-Trich16 & 33.0 & 26.1 & 17.0 & 24.0 & 50.1 & 789.0 \\
\hline MNF-MSH-Trich17 & 21.6 & 25.9 & 27.1 & 25.4 & 50.3 & 874.0 \\
\hline MNF-MSH-Trich18 & 22.5 & 25.0 & 24.1 & 28.4 & 53.4 & 756.0 \\
\hline MNF-MSH-Trich19 & 23.3 & 29.3 & 22.2 & 25.2 & 54.5 & 662.0 \\
\hline MNF-MSH-Trich20 & 23.1 & 31.2 & 21.5 & 24.2 & 55.4 & 637.0 \\
\hline MNF-MSH-Trich21 & 22.9 & 26.9 & 22.7 & 27.5 & 54.4 & 673.0 \\
\hline MNF-MSH-Trich22 & 27.4 & 24.8 & 26.2 & 21.7 & 46.5 & 577.0 \\
\hline MNF-MSH-Trich23 & 32.5 & 24.3 & 25.2 & 17.9 & 42.2 & 658.0 \\
\hline MNF-MSH-Trich24 & 22.1 & 29.6 & 22.1 & 26.2 & 55.8 & 714.0 \\
\hline MNF-MSH-Trich25 & 20.8 & 22.0 & 26.8 & 30.4 & 52.4 & 998.0 \\
\hline MNF-MSH-Trich26 & 24.6 & 27.0 & 23.7 & 24.6 & 51.6 & 877.0 \\
\hline MNF-MSH-Trich27 & 31.5 & 24.4 & 26.0 & 18.2 & 42.6 & 731.0 \\
\hline MNF-MSH-Trich28 & 26.6 & 24.1 & 22.6 & 26.7 & 50.8 & 888.0 \\
\hline
\end{tabular}

Table 6: Nucleotide Frequencies in Percent of the sequences of ITS1-5.8S-ITS2 regions analyzed using Molecular Evolutionary Genetics Analysis (MEGA4 version 5.20.) for 28 Trichoderma isolates.

synergistic actions involving $\beta$-glucosidase and cellobiohydrolases [46]. Walseth cellulose plate assay included converting the crystalline fraction of cellulose to the amorphous form by adding o-phosphoric acid to produce phosphoric acid swollen cellulose (PASC) [47]. None of screening methods reported in this research had sufficient precession to allow the selection of particular cellulase enzymes. This is may be due to the complexity of the celluletic system produced by Trichoderma. However, eleven isolates were selected to be the best isolates among the 28 isolates used. These are MNF-MSH-Trich1, MNF-MSH-Trich5, MNF-MSH-Trich7, MNF-MSH-Trich8, MNF-MSH-Trich9, MNFMSH-Trich10, MNF-MSH-Trich14, MNF-MSH-Trich21, MNF-MSHTrich22, MNF-MSH-Trich26 and MNF-MSH-Trich27. These findings were consistent with the result that most of the isolates were belonging to T. longibarchiatum and T. harzianum. These species have been adopted in various industries because of their ability to secrete large amounts of protein and metabolites [4].

\section{Conclusion}

According to this investigation results, the morphological characterization is not reliable for identification of the isolates and oligonucleotide barcode is a powerful tool for the identification of Trichoderma species and should be useful as an alternative or as a complement to morphological methods. According to molecular findings there were two main species predominated in the middle Delta area of Egypt namely; T. longibarchiatum and T. harzianum. Eleven

\begin{tabular}{|c|c|c|c|c|}
\hline \multirow{2}{*}{$\begin{array}{l}\text { Trichoderma } \\
\text { isolate }\end{array}$} & \multicolumn{2}{|c|}{ Endonuclease* } & \multirow{2}{*}{$\begin{array}{c}\text { Exoglucanases } \\
\text { Avicel * }\end{array}$} & \multirow{2}{*}{$\begin{array}{l}\text { Total cellulase } \\
\text { (Cellulose } \\
\text { azure record) }\end{array}$} \\
\hline & $\begin{array}{l}\text { Swollen } \\
\text { cellulose }\end{array}$ & CMC & & \\
\hline MNF-MSH-Trich1 & $5.30^{a}$ & $5.33^{\text {fgh }}$ & $5.43^{a}$ & 9 \\
\hline MNF-MSH-Trich2 & $4.83^{\mathrm{bcd}}$ & $5.40 \mathrm{fg}$ & 4.63 cdef & 10 \\
\hline MNF-MSH-Trich3 & $4.20^{g}$ & 4.97 ghij & $3.73^{i j}$ & 8 \\
\hline MNF-MSH-Trich4 & $2.06^{k}$ & 5.97 de & $1.73 \mathrm{lmn}$ & 9 \\
\hline MNF-MSH-Trich 5 & 4.77 cde & $6.67^{a b}$ & 4.63 cdef & 10 \\
\hline MNF-MSH-Trich6 & 4.67 ddef & $4.17^{\prime}$ & $3.73^{i j}$ & 9 \\
\hline MNF-MSH-Trich7 & $3.73^{\mathrm{hi}}$ & $6.50 \mathrm{abc}$ & $5.03 a b c$ & 10 \\
\hline MNF-MSH-Trich8 & $5.10 \mathrm{abc}$ & $6.30 \mathrm{bcd}$ & $5.00 \mathrm{abcd}$ & 10 \\
\hline MNF-MSH-Trich9 & 4.80 cde & 6.70 ab & $4.73^{\text {cdef }}$ & 10 \\
\hline MNF-MSH-Trich10 & $4.23 \mathrm{fg}$ & $6.67^{a b}$ & 4.47 efg & 10 \\
\hline MNF-MSH-Trich11 & $3.60^{\text {hi }}$ & $3.20 \mathrm{~m}$ & $3.33^{j}$ & 8 \\
\hline MNF-MSH-Trich12 & $3.57^{i}$ & 5.63 ef & 3.97 hi & 8 \\
\hline MNF-MSH-Trich13 & 4.37 efg & $6.20^{\mathrm{cd}}$ & 4.50 ef & 9 \\
\hline MNF-MSH-Trich14 & $5.40^{a}$ & $6.53^{a b c}$ & $5.45^{a}$ & 10 \\
\hline MNF-MSH-Trich15 & $2.07^{k}$ & $5.10 \mathrm{ghi}$ & $1.73 \mathrm{lmn}$ & 8 \\
\hline MNF-MSH-Trich16 & $4.20^{g}$ & $6.17^{\mathrm{cd}}$ & $1.30^{n}$ & 7 \\
\hline MNF-MSH-Trich17 & $2.00^{k}$ & 5.20 fghi & $1.97 \mathrm{kl}$ & 7 \\
\hline MNF-MSH-Trich18 & $2.00^{k}$ & $4.37^{\mathrm{kl}}$ & $3.77^{\mathrm{ij}}$ & 8 \\
\hline MNF-MSH-Trich19 & $4.43^{\text {defg }}$ & 6.00 de & 4.65 def & 10 \\
\hline MNF-MSH-Trich20 & $2.00^{k}$ & $2.80^{\mathrm{m}}$ & $1.8^{\mathrm{Im}}$ & 8 \\
\hline MNF-MSH-Trich21 & $4.03^{\mathrm{gh}}$ & $6.77^{\mathrm{a}}$ & $4.03 \mathrm{ghi}$ & 10 \\
\hline MNF-MSH-Trich22 & $5.10 \mathrm{abc}$ & $4.93^{\text {hij }}$ & $5.23^{a b}$ & 10 \\
\hline MNF-MSH-Trich23 & $3.00^{j}$ & $4.27^{\prime}$ & $1.37 \mathrm{mn}$ & 9 \\
\hline MNF-MSH-Trich24 & $1.36^{\prime}$ & 6.03 de & $2.27^{k}$ & 7 \\
\hline MNF-MSH-Trich25 & 4.70 cde & $5.10 \mathrm{ghi}$ & $4.33 \mathrm{fgh}$ & 8 \\
\hline MNF-MSH-Trich26 & $5.27^{a b}$ & $4.53^{\mathrm{jkl}}$ & $5.3^{a}$ & 10 \\
\hline MNF-MSH-Trich27 & $5.00 a b c$ & $4.77^{\mathrm{ijk}}$ & $4.8^{\text {bcde }}$ & 10 \\
\hline MNF-MSH-Trich28 & $2.08^{k}$ & $4.26^{\prime}$ & 3.98 hi & 8 \\
\hline
\end{tabular}

* Clear zone diameter in $\mathrm{cm}$, Values within a column followed by the same letter (s) are not significantly different at $p<0.05$ level according to the Duncan's multiple range test (DMRT).

"Standard color scale of 1 (minimum) to 10 (maximum) [25].

Table 7: Total cellulase, endoglucanases and exoglucanases (cellobiohydrolases) enzymes activities of Trichoderma isolates.

isolates were selected to be the best isolates among the 28 isolates used for cellulolytic activity.

\section{Acknowledgements}

Authors are very grateful to Menoufia University for funding this project (Project name: "The use of biotechnology in the biological treatment of agricultural waste and the production of bio-fertilizers", Funding applied research project program).

\section{References}

1. Samuels GJ (2006) Trichoderma: systematics, the sexual state, and ecology Phytopathology 96: 195-206.

2. Sivasithamparam K, Ghisalberti EL (1998) Secondary metabolism in Trichoderma and Gliocladium. Basic biology 1: 139-191.

3. Prabavathy V, Mathivanan N, Sagadevan E, Murugesan K, Lalithakumari D (2006) Self fusion of protoplasts enhances chitinase production and biocontrol activity in Trichoderma harzianum. Bioresour Technol 97: 2330-2334.

4. Gupta VG, Schmoll M, Herrera-Estrella A, Upadhyay RS, Druzhinina I (2014) Biotechnology and Biology of Trichoderma. Elsevier 5: 16-332.

5. Ghose TK (1987) Measurement of cellulase activities. Pure Appl Chem 59 257-268.

6. Pointing SB (1999) Qualitative methods for the determination of lignocellulolytic enzyme production by tropical fungi. Fungal Divers 2: 17-33. 
Citation: Fahmi Al, Eissa RA, El-Halfawi KA, Hamza HA, Helwa MS (2016) Identification of Trichoderma spp. by DNA Barcode and Screening for Cellulolytic Activity. J Microb Biochem Technol 8: 202-209. doi: 10.4172/1948-5948.1000286

7. Kim CH, Kim DS (1995) Purification and specificity of a specific endo-b-,4 D-glucanase (avicelase II) resembling exo-cellobiohydrolase from Bacillus circulans. Enzyme Microb Technol. 17: 248-254.

8. Florencio F, Couri S, Farinas CS (2012) Correlation between Agar Plate Screening and Solid-State Fermentation for the Prediction of Cellulase Production by Trichoderma Strains. Enzyme Research 2012: 1-7.

9. Teather RM, Wood PJ (1982) Use of Congo red-polysaccharide interactions in enumeration and characterization of cellulolytic bacteria from the bovine rumen. Appl Environ Microbiol 43: 777-780.

10. Kovacs K, Megyeri L, Szakacs G , Kubicek CP, Galbe M, et al. (2008) Trichoderma atroviride mutants with enhanced production of cellulase and ß-glucosidase on pretreated willow. Enzyme and Microb Technol 43: 48-55.

11. Samuels GJ, Chaverri P, Farr DF, McCray EB (2002) Trichoderma Online. Systematic Mycology and Microbiology Laboratory, ARS, USDA

12. Samuels GJ, Ismaiel A, Bon MC, De Respinis S, Petrini O (2010) Trichoderma asperellum sensu lato consists of two cryptic species. Mycologia 102: 944-966.

13. Druzhinina IS, Kopchinskiy AG, KomoÅ, M, Bissett J, Szakacs G, et al. (2005) An oligonucleotide barcode for species identification in Trichoderma and Hypocrea. Fungal Genet Biol 42: 813-828.

14. Schoch CL, Seifert KA, Huhndorf S, Robert V, Spouge JL, et al. (2012) Nuclear ribosomal internal transcribed spacer (ITS) region as a universal DNA barcode marker for Fungi. Proc Natl Acad Sci. 109: 6241-6246.

15. Lieckfeldt E, Kuhls K, Muthumeenakshi S (2002) Molecular taxonomy of Trichoderma and Gliocladium and their teleomorphs. Taylor \& Francis Ltd, London.

16. White TJ, Bruns T, Lee S, Taylor J (1990) Amplification and direct sequencing of fungal ribosomal RNA genes for phylogenetics. San Diego, Calif, Academic Press.

17. Chakraborty BN, Chakraborty U, Saha A, Dey PL, Sunar K (2010) Molecular characterization of Trichoderma viride and Trichoderma harzianum isolated from soils of North Bengal based on rDNA markers and analysis of Their PCRRAPD profiles. Global J Biotech \& Biochem. 5: 55-61.

18. Lee CF, Hseu TH (2002) Genetic relatedness of Trichoderma sect. Pachybasium species based on molecular approaches. Can J Microbiol 48: 831-840.

19. Lakshmi NRP, Babu BS, Radhaiah A, Sreeramulu A (2014) Screening Identification and Isolation of Cellulolytic fungi from soils of Chittoor District, India. Int J Curr Microbiol App Sci 3: 761-771.

20. Aneja KR (2005) Cultivation techniques for isolation and enumeration of microorganisms. New Age International publishers, New Delhi.

21. Dhingra OD, Sinclair JB (1985) Culture of pathogen In: Basic plant pathology methods. (2 $\left.{ }^{\text {nd }} \mathrm{Edn}\right) \mathrm{CRC}$ Press, Brazil.

22. Rahman A, Begum MF, Rahman M, Bari MA, llis GNM, et al. (2011) Isolation and identification of Trichoderma species from different habitats and their use for bioconversion of solid waste. Turk J Biol. 35: 183-194.

23. Fahmi Al, Al-Talhi AD, Hassan MM (2012) Protoplast fusion enhances antagonistic activity in Trichoderma spp. Nature and Science 10: 100-106.

24. Barnett HL, Hunter BB (1998) Illustrated genera of imperfect fungi. (4th edn) The American Phytopathological Society, St Paul, APS Press, Minnesota, USA.

25. Hermosa MR, Grondona I, Iturriaga EA, Diaz-Minguez JM, Castro C, et al (2000) Molecular characterization and identification of biocontrol isolates of Trichoderma spp. Appl Environ Microbiol 66: 1890-1898.

26. Khiyami MA, Bahkali AH (1996) Evaluation of method for screening of extracellular cellulase in filamentous fungi. Qatar Univ Sci J 16: 285-290.

27. Bose RG (1963) A modified cellulosic medium for the isolation of cellulolytic fungi from infected materials and soils. Nature 198: 505-506.

28. Mandels M, Andreotti R, Roche C (1976) Measurement of saccharifying cellulase. Biotechnol Bioeng Symp : 21-33.

29. Peterson R, Grinyer J, Joss J, Khan A, Nevalainen H (2009) Fungal proteins with mannanase activity identified directly from a Congo Red stained zymogram by mass spectrometry. J Microbiol Methods 79: 374-377.

30. Rautela GS, Cowling EB (1966) Simple cultural test for relative cellulolytic activity of fungi. Appl Microbiol 14: 892-898.
31. Anees M, Tronsmo A, Edel-Hermann V, Hjeljord LG, Héraud C, et al (2010) Characterization of field isolates of Trichoderma antagonistic agains Rhizoctonia solani. Fungal Biol 114: 691-701.

32. Shahid M, Srivastava M, Kumar V, Singh A, Sharma A, et al. (2014) Phylogenetic diversity analysis of Trichoderma species based on internal transcribed spacer (ITS) marker. Afr J Biotechnol. 13: 449-455.

33. Diguta CF, Vincent B, Guilloux-Benatier M, Alexandre H, Rousseaux S (2011) PCR ITS-RFLP: A useful method for identifying filamentous fungi isolates on grapes. Food Microbiol 28: 1145-1154.

34. Kullnig-Gradinger CM, Szakacs G, Kubicek CP (2002) Phylogeny and evolution of the genus Trichoderma: a multigene approach. Mycol Res. 106: 757-767.

35. Druzhinina I, Kubicek CP (2005) Species concepts and biodiversity in Trichoderma and Hypocrea: from aggregate species to species clusters? Zhejiang Univ Sci B 6: 100-112.

36. Gherbawy Y, Druzhinina I, Shaban GM, Wuczkowsky M, Yaser M, et al. (2004) Trichoderma populations from alkaline agricultural soil in the Nile valley, Egypt, consist of only two species. Mycological Progress 3: 211-218.

37. Abo-Elyousr KAM, Abdel-Hafez SII, Abdel-Rahim IR (2014) Isolation of Trichoderma and evaluation of their antagonistic potential against Alternaria porri. J Phytopathol 162: 567-574.

38. Druzhinina IS, Komo $\AA$,-Zelazowska M, Ismaiel A, Jaklitsch W, Mullaw $T$ et al. (2012) Molecular phylogeny and species delimitation in the section Longibrachiatum of Trichoderma. Fungal Genet Biol 49: 358-368.

39. Samuels GJ, Ismaiel A, Mulaw TB, Szakacs G, Druzhinina IS, et al. (2012) The Longibrachiatum Clade of Trichoderma: a revision with new species. Fungal Divers 55: 77-108.

40. BÅ,aszczyk L, Popiel D, CheÅ,kowski J, Koczyk G, Samuels GJ, et al. (2011) Species diversity of Trichoderma in Poland. J Appl Genet 52: 233-243.

41. Khokhar I, Haider MS, Mushtaq S, Mukhtar I (2012) Isolation and screening of highly cellulolytic filamentous fungi. Scholarly Journal of Agricultural Science 2: 126-129.

42. Smith RE (1977) Rapid tube test for detecting fungal cellulase production. App Environ Microbiol 33: 980-981.

43. Fadel M (2000) Production physiology of cellulases and ß-glucosidase enzymes of Aspergillus niger grown under solid state fermentation conditions. Online Journal of Biological Sciences 1: 401-411.

44. Sharrock KR1 (1988) Cellulase assay methods: a review. J Biochem Biophys Methods 17: 81-105.

45. Thormann CE, Ferreira ME, Camargo LE, Tivang JG, Osborn TC (1994) Comparison of RFLP and RAPD markers to estimating genetic relationships within and among cruciferous species. Theor Appl Genet 88: 973-980.

46. Lynd LR, Weimer PJ, van Zyl WH, Pretorius IS (2002) Microbial cellulose utilization: fundamentals and biotechnology. Microbiol Mol Biol Rev 66: 506577 , table of contents.

47. Wood TM (1988) Preparation of crystalline, amorphous and dyed cellulose substrates. Methods in Enzmology. 166: 19-25. 